\title{
Markedness Approach to the Production of English Consonant Clusters Among the Libyan Arabic Speakers of English
}

\section{Mr. Mohamed Abdalla Elsaghayer \\ Misurata University}

\begin{abstract}
The study was conducted at the Language Centre of Misurata University, to investigate the 'markedness' effect of articulating CCC clusters in onset, and CC, CCC clusters in coda, among Libyan speakers of English. Eckman's 'Markedness Differential Hypothesis' was employed as a theoretical framework to investigate the problem. The instruments used were a list of words containing the target consonant clusters, and unstructured interviews of the participants. 20 students, all studying at the intermediate level at Misurata University Language Centre, participated in the study. The speech samples were analyzed to identify the difficulty of pronouncing the target clusters, and their deviation in Libyans' English speech. The CCC clusters in the onset and both CC and CCC in coda were the most difficult sounds to articulate. The answer to the research questions was clear that the Libyan speakers of English do have difficulty in articulating the complex consonant clusters because of their absence in their L1. The results of the study clearly prove and support markedness hypothesis. Some recommendations have been made to improve the pronunciation in the areas identified in the present study.
\end{abstract}

\section{Introduction}

Arabic language and English language descend from two different language families and are quite different in several areas, although we can find cases of some resemblance. These differences certainly lead to difficulty, if we consider the assumption that when languages are different, learning becomes difficult and vice versa. The L1 of the Libyan speakers of English is Libyan Arabic which lacks the complex consonant clusters which English has. Therefore the English they speak is affected by the transfer of their L1 phonological features. Hence Eckman's 'Markedness Differential Hypothesis' has been chosen as a theoretical framework for the study. 


\section{The Markedness Differential Hypothesis (MDH)}

As the MDH has been chosen as a theoretical framework, it is relevant to state the theory here. Eckman postulated this theory to explain why ESL / EFL learners transferred some of the phonological features that existed in their L1 on to the target language. His theory will be stated here in full: The areas of difficulty that a language learner will have can be predicted on the basis of a systematic comparison of the grammars of the native language, the target language and the markedness relations stated in universal grammar such that,

a. Those areas of the target language which differ from the native language and are more marked than the native language will be difficult.

b. The relative degree of difficulty of the areas of the target language which are more marked than the native language will correspond to the relative degree of markedness.

c. Those areas of the target language which are different from the native language, but are not more marked that the native language will not be difficult (Eckman 1977:61)

The MDH, therefore, can predict an area of difficulty when there is a difference between the native language and target language and the target language is relatively more marked.

A brief Inventory of the Consonant clusters in Libyan Arabic and
English
\begin{tabular}{|l|l|}
\hline Consonant clusters in English : & Consonant clusters in Libyan Arabic : \\
CV, CCV, CCCV in onset. & CV, VC, CVC, CCVC \\
VC, VCC, VCCC, VCCCC in coda. & Maximum C in onset is CC \\
Maximum phonological structure in & Maximum C in coda is C \\
English is : CCCVCCCC & Maximum phonological structure in \\
& Libyan Arabic is : CCVC \\
\hline
\end{tabular}

\section{Standard Arabic and Libyan Dialect}

It would be necessary to understand the kind of Arabic spoken in Libya, to understand the nature of its transfer. There are no research works done on the Libyan L1 interference in spoken English.

Arabic spoken in Libya is very much different from the standard Arabic. To give a clear picture, I would like to quote Watson : 
The original homeland of speakers of Arabic is the central and northern regions of Arabian peninsula... The end of $16^{\text {th }}$ century CE, saw the rise of Islam promoted by the Prophet Mohammed, within the Arabian peninsula in what is now Saudi Arabia. The new Islamic state spread rapidly throughout the peninsula... and west into north Africa...In north, Arabic became the dominant language of the cities... Now Arabic is the sole or joint official language in 20 countries stretching from West Asia to North Africa. (Watson,2007:6)

Waston (2007:7)further observes:

Unlike many such languages, however, no one in the Arab world is brought up speaking standard Arabic as their mother tongue: an Arab child's mother tongue will be the original or social variety of Arabic of its home region ... standard Arabic is confined to formal written and spoken occasions.

\section{Significance of the Study}

To the best of my knowledge, there has been no study conducted on the markedness effect on the production of consonant clusters, it will :

a. Create an awareness among the EFL teachers in Libya.

b. Help the course book writers and educationists to incorporate the cluster problems the learners face and take remedial measures, in the materials.

\section{Statement of the Problem}

Usually a Libyan speaker of English splits a CCC cluster in onset and CC or CCC clusters in coda, with an epenthesis and replacing some phonemes with others, leading to unintelligibility of the speech. Libyan speakers' L1 is Libyan Arabic which differs vastly from the standard Arabic. And again, English consonant clusters are too difficult for the Libyans to articulate and hence the transfer of the L1 phonological features onto the target language.

\section{Research questions}

The research aims to find answers to the following questions

1. Why do Libyan speakers of English split CCC cluster with an epenthesis in onset? Is it because their L1 does not have such clusters? 
2. Why do Libyan speakers of English use an epenthesis splitting the CC or CCC in word-final positions? Is it because they do not have such clusters in their L1?

3. Why does CC not pose any difficulty in the onset or word-initial position? Is it because they have such clusters in their L1?

\section{Related literature}

English consonant clusters often pose a problem for non-native speakers of English, whose languages do not allow consonant clusters of the kind English allows. Recently, attention has been paid to the acquisition of English consonant clusters by non-native speakers of English. Research in this area attempts to account for acquisition data in two respects: transfer of the native language (L1) and 'markedness' effects on the developmental processes in second language acquisition.

Since Eckman (1977) applied the concept 'markedness' in the analysis of the acquisition data, the role of markedness has been examined in the area of syllable structure. The more complex (therefore more marked) consonant clusters seem to incur more errors than simpler one. There are numerous studies about the influence of language universals in interlanguage phonology; particularly studies relating to markedness. I will discuss some of the important issues from the literature that are relevant to the current study. As mentioned in the introduction, there have been claims about the roles of transfer of the first language structure (Lado 1957) and markedness since the 1970's when Eckman (1977) proposed Markedness Differential Hypothesis (MDH). There have been different interpretations of the concept 'Markedness' within different linguistic theoretical frameworks. However, markedness in interlanguage phonology is strongly implicational: $x$ is more marked than $y$ if the presence of $x$ implies the presence of $y$ but not vice versa. For example, CCC clusters are more marked than $\mathrm{CC}$ clusters since presence of $\mathrm{CCC}$ implies the presence of CC.

Weinberger (1987) examined modifications of codas of different lengths produced by 4 adult Mandarin speakers and found that the frequency of modification increased linearly with the length of the coda, since the longer margin is more marked. In his study, $5.5 \%$ of one member codas, $29.8 \%$ of two member codas and $42 \%$ of three member codas were modified. Eckman (1991) provided a similar result, in an investigation of Korean, Japanese, and Cantonese speakers of English. Along the same 
lines as Eckman (1991), Carlisle (1997) conducted extensive works on the markedness relationship in the acquisition of onset clusters by Spanish learners of English. He found that three member onsets (spr, strskr) are more frequently modified than two member onsets ( $\mathrm{pr}, \mathrm{tr}, \mathrm{kr}$ ). In addition, Carlisle (1998) conducted a 10 month longitudinal study of 10 Spanish speakers producing the above mentioned onset clusters. He attempted to test markedness by measuring acquisition against a criterion of $80 \%$ correct production, which means that if a structure is produced correctly $80 \%$ of the time, it is considered to be acquired. He also considered the relation between the difficulty and the violation of Universal Canonical Syllable Structure (UCSS) which constrains sonority within a syllable. Syllable onsets and codas satisfy UCSS if the sonority of the clusters increases continuously through the nucleus. English has some onsets violating UCSS: two member onsets such as /sp, st, sk/ and three member onsets. Carlisle (1988) and Tropf (1987) asserted that learners modify the /s/-clusters more frequently than other clusters that conform to UCSS. Asymmetry between onset and coda in the degree and strategy choice of cluster simplification has been reported by Anderson (1987), For example, with reference to native speakers of Egyptian Arabic, Amoy and Mandarin Chinese, Anderson (1987) found that all these groups modified longer margins and between coda and onset, coda clusters are more simplified than the onset, providing evidence for the relative markedness relationship between onset and coda. The Chinese speakers modified 10\% of two member onsets but $50 \%$ of two member codas. In addition, insertion is favored in onset, while deletion is favored in coda.

Choice of simplification strategy has been an issue in interlanguage phonology and generally the choice was regarded as a transfer of native language background. Studies reported different patterns cross-linguistically in the choice of strategies: Korean, Vietnamese, Chinese, and Arabic learners of English favored deletion most in the simplification of coda clusters (Anderson 1987), whereas Portuguese and Japanese learners favored epenthesis (Weinberger 1987). More recent studies on consonant clusters have looked at cluster types more closely and explanations have become more complex. Broselow et al. (1998) observed Chinese learners of English favored insertion for monosyllabic words and deletion and devoicing for disyllabic words.

Production accuracy could be affected by the formality of the tasks. Numerous studies in variation claim there is an increase in the frequency 
of standard forms in more formal situations. In other words, the amount of L1 transfer decreases as style becomes more formal (Major 2001). In his experimental study, Eckman (1991) found that speakers performed better in word lists than sentence lists or conversations. There are other studies that do not support the difference due to formality:

Even though acquisition order in interlanguage phonological development has been an issue, research often examined the processes from one-time data and few longitudinal studies (Sato 1984; Hansen 2003) have been conducted on the consonant clusters discussed in the present study. Recently, Hansen (2003), examining a longitudinal development of codas by 2 Vietnamese speakers over a year, found the data generally conform to the markedness relationship but the sequences are not in a linear order: for example, some two or three member codas emerge earlier than singleton codas.

As most of the studies mentioned so far have examined the reduced clusters made by a few speakers of different language backgrounds in the ESL environment, they have certain limitations. Although they show cross-linguistic patterns, they are not necessarily representative of learners of a particular language background. Generalizations from a larger number of learners in the EFL environment may be different from the earlier findings. There have been many studies about Korean learners learning English in Korea, but findings are inconsistent: Kim (1991) found that Korean middle school students use more insertion in coda. Lee et al. (2002), in their study of Korean university students, confirmed the earlier findings in general except that most prominent error type is replacement, rather than epenthesis or deletion.

\section{Methodology}

\section{Participants and Sample Collection}

Twenty students, of whom 10 were girls, studying at the intermediate level, in the Language Centre of Misurata University, were randomly selected to participate in the study. Each participant was given the passage containing the target clusters and asked to read. The readings were recorded as they read. Each participant was also interviewed, in an unstructured manner, which also was recorded, for spontaneous utterances of the target clusters. The samples were then phonemically transcribed. 
The target clusters were picked up for analysis. The participants were informed that their speech samples would be used in an experiment.

\section{Instruments}

A list of the phonemically transcribed target clusters- CC,CCC in onset and CC,CCC in coda, based on the samples from the passages and interviews, was used for analysis.

\section{Results and Discussion}

For the purpose of analysis of the clusters the phonetic transcriptions given in the Oxford Learners' Dictionary was used for reference. The target consonant clusters have been studied in detail and tabulated.

\section{Table-1}

Speech samples of CC, CCC in coda

\begin{tabular}{|c|c|c|}
\hline Words & $\begin{array}{l}\text { RP phonetic } \\
\text { transcription }\end{array}$ & Libyan deviation \\
\hline Bumps & $\mathrm{b} \Lambda \mathrm{mps}$ & $\mathrm{b} \wedge \mathrm{mb} \partial \mathrm{z})$ \\
\hline Trained & treind & Tre:nəd \\
\hline Talks & to:ks & təkəs \\
\hline Things & $\theta \operatorname{inz}$ & t ingIz \\
\hline friends & frendz & frendiz \\
\hline Films & frlmz & FIlməz \\
\hline sometimes & səmtaImz & səmtaiməz \\
\hline Thanks & $\theta æ \eta \mathrm{ks}$ & tænkəs \\
\hline programs & prəugræmz & brəugræməz \\
\hline
\end{tabular}




\begin{tabular}{|l|l|l|}
\hline removes & ri:mu:vz & ri:mu:vəz \\
\hline Tables & terblz & terbələz \\
\hline washed & woft & wp fid \\
\hline clapped & klæpt & klæbid \\
\hline
\end{tabular}

L1 transfer is noted, distinctly, in two areas:

a) Splitting of the two consonant and three consonant clusters in the word- final, coda, positions

b) Problems in articulating and producing three consonant clusters in word-initial, onset, positions.

The analytical tables are presented in the pages that follow.

Table-2

Examination of the $\mathrm{CC}$ clusters in coda

\begin{tabular}{|c|c|c|c|}
\hline Words & $\begin{array}{c}\text { Final cluster } \\
\text { CC }\end{array}$ & $\begin{array}{c}\text { Split in Libyan } \\
\text { English }\end{array}$ & $\begin{array}{c}\text { Libyan deviation } \\
\text { In \% }\end{array}$ \\
\hline removes & $--\mathrm{VZ}$ & $--\mathrm{v} \partial \mathrm{Z}$ & $71 \%$ \\
\hline talks & $--\mathrm{ks}$ & $-\mathrm{k} ə \mathrm{~s}$ & $71 \%$ \\
\hline sometimes & $--\mathrm{mz}$ & məz & $72 \%$ \\
\hline programs & prəugræmz & brəgræməz & $76 \%$ \\
\hline things & $\theta \mathrm{Inz}$ & -- gəz & $72 \%$ \\
\hline
\end{tabular}

Average split with an epenthesis is $71.4 \%$

Note: / I / and / o / are often interchanged. There is no consistency in their use.

Practically, all the clusters in the word-final positions are split, inserting a schwa /a/ between the last two consonants. In Table-1, above some clusters have three consonants and some have two. 
Table-3

Examination of the $\mathrm{CCC}$ clusters in coda

\begin{tabular}{|c|c|c|c|}
\hline Words & Final cluster $\mathrm{CCC}$ & $\begin{array}{l}\text { Split in } \\
\text { Libyan } \\
\text { English }\end{array}$ & $\begin{array}{c}\text { Libyan } \\
\text { deviation } \\
\text { In } \% \\
\end{array}$ \\
\hline thanks & 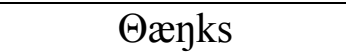 & $--1 \mathrm{k} \partial \mathrm{s}$ & $71 \%$ \\
\hline films & filmz & $--\operatorname{lm} \partial z$ & $71 \%$ \\
\hline bumps & $\mathrm{b} \Lambda \mathrm{mps}$ & --mbəz) & $76 \%$ \\
\hline tables & terblz & --bloz & $71 \%$ \\
\hline friends & frendz & --ndiz & $72 \%$ \\
\hline
\end{tabular}

Average split is $72.2 \%$

As it can be seen from the Tables-2 and 3, whether the clusters in the word-final position are $\mathrm{CC}$ or $\mathrm{CCC}$, the split occurs, with the insertion of $/ \mathrm{a} / \mathrm{or} / \mathrm{I} /$ between the last two consonants. How can this be explained? One possible explanation is that the Arabic spoken in Libya does not have consonant clusters in the final position. A Libyan speaker is normally used to $\mathrm{VCV}, \mathrm{CCVC}$ or CVVC combinations. It is this instinctive habit that is responsible for splitting the clusters with a /a/ or an / I / So, absence of these clusters in their L1, which become more marked poses a great difficulty in articulating these clusters. Splitting the clusters is clearly an L-1 transfer.

\section{Table-4}

Split of CC in the past form of verbs ending in unvoiced consonants + ed

\begin{tabular}{|c|c|c|}
\hline verbs & transcription & $\begin{array}{c}\text { Libyan deviation } \\
\text { In \% }\end{array}$ \\
\hline book & bokt & bokəd $80 \%$ \\
\hline watched & wpt ft & wD Id $85 \%$ \\
\hline washed & wp ft & wD Id $85 \%$ \\
\hline clapped & klæpt & klæbid $84 \%$ \\
\hline
\end{tabular}

Average deviation $85.4 \%$

What is interesting is the split in the CC of the past form of the verbs ending in voiceless consonants. It is interesting because if pronounced correctly, the past forms end in / $t$ /. But a Libyan speaker of English is not aware of this fact and goes by the logic of regular verbs ending with -ed 
to form the past form which they usually pronounce as /-id/. The second factor, which seems to be more logical, is the orthography where they see it as a regular verb form ending with -ed. Or even if they are aware of the verbs ending with -ed to be as $/ t /$, it is their unconscious habit of splitting $\mathrm{CC}$ in coda, that is responsible for this feature.

\section{Table -5}

Examination of $\mathrm{CC}$ and $\mathrm{CCC}$ clusters in the onset positions.

\begin{tabular}{|c|c|c|}
\hline Words & $\begin{array}{l}\text { RP } \\
\text { Phonetic transcription }\end{array}$ & $\begin{array}{l}\text { Libyan deviation - } \\
\text { L1 interference }\end{array}$ \\
\hline Pray & preI & ------------ \\
\hline Plum & $\mathrm{pl} \Lambda \mathrm{m}$ & ------------- \\
\hline Tree & tri: & -------------- \\
\hline Speak & spi:k & -------------- \\
\hline Cream & kri:m & -------------- \\
\hline Flag & Flæg & ------------- \\
\hline School & sku:1 & -------------- \\
\hline Brown & braon & ------------- \\
\hline Splash & splæ $\int$ & Isblæ $66 \%$ \\
\hline Scream & skri:m & Iskri:m $67 \%$ \\
\hline Square & skweI & IskweIr $63 \%$ \\
\hline Spray & spreI & IspreI $64 \%$ \\
\hline Strong & stron & Istroyg $65 \%$ \\
\hline
\end{tabular}

Average split is $65 \%$

The samples in the table above clearly show that there is no problem in articulating and producing the word initial two-consonant clusters. This is 
because there are many combinations of two initial consonant clusters in Libyan dialect.

The three consonant clusters are split. The problem here is altogether different: the three consonant clusters which always start with /s/ begin with an /i/ sound. This does not happen with a cluster starting with /s /, if it has only CC because Libyan Arabic has CC clusters in the onset. See table 6 below, where some Libyan Arabic CC clusters are presented. What could be the reason for splitting a CCC cluster in the onset? Firstly, Libyan Arabic does not have any CCC in the word initial position. The second reason, which seems to be stronger, is producing a CCC in a quick succession, is a difficult task. So, starting with an / i/ makes it easier to articulate the CCC clusters. But by starting with an /i/ a speaker splits the cluster. It would practically be : / is-pred/ /is-kw / /is-kri:m/ . This again, is a clear demonstration of the transfer of the phonological features of L1 onto the target language. This again proves the markedness effect.

Table 6, below shows some examples of two consonant clusters in the initial position of some Libyan words.

\section{Table 6}

\begin{tabular}{|c|c|c|}
\hline $\begin{array}{c}\text { A combination of two } \\
\text { consonant in the initial } \\
\text { position }\end{array}$ & $\begin{array}{c}\text { Libyan words in } \\
\text { phonetic transcription }\end{array}$ & The meaning \\
\hline $\mathrm{Kl}$ & klæm & Talking \\
\hline $\mathrm{Bl}$ & $\mathrm{blæ} \int$ & $\begin{array}{c}\text { free (costing } \\
\text { nothing) }\end{array}$ \\
\hline $\mathrm{Sb}$ & sbu:l & $\begin{array}{c}\text { spaull ( a bunch } \\
\text { of barley) }\end{array}$ \\
\hline $\mathrm{Sw}$ & Swer & Photos \\
\hline $\mathrm{Fr}$ & fræ & Bed \\
\hline $\mathrm{Sk}$ & skən & Lived \\
\hline $\mathrm{Kr}$ & kre:mah & Cream \\
\hline $\mathrm{Sm}$ & smi:n & Fat \\
\hline $\mathrm{Tr}$ & trə & let me see \\
\hline
\end{tabular}




\section{Findings}

The analysis carried out so far clearly shows that there is sufficient evidence to state that the Libyan Arabic speakers of English do have a great difficulty in articulating English consonant clusters which are marked, resulting in the transfer of the L1 feature on their spoken English. The markedness of the clusters, therefore the difficulty, is seen in three specific areas:

a. in onset if it is a CCC cluster, $(65 \%)$

b. in coda if it is a CC (71\%) or CCC (72\%)

CCCC clusters have not been studied as their occurrence is not very frequent.

c. in the past form of the verbs ending unvoiced consonants + ed $(83.5 \%)$

\section{Conclusion}

Clear pronunciation is very important for mutual intelligibility. In English complex consonant clusters occur very frequently. As the findings reveal the Libyan speakers of English face great difficulties in articulating these clusters. Consequently, they transfer the L1 consonant structures on to their spoken English which result in lack of intelligibility. In order to be intelligible, they have got to overcome these difficulties. The markedness nature of the English consonant clusters should be positively considered by both the EFL teachers and learners.

\section{Recommendations}

Libya does not have a long tradition of speaking English, either for general or official communication. So, one cannot pick up English from the immediate environment. Practically, all the speakers have formal, school or university education. Therefore, the correction has to come from educational institutes, and specifically from the schools, as it is there that the speakers are first trained in spoken English skills, which take deep roots in their minds. The following techniques and methods can be effective:

1) A one- week, intensive training program in phonetics and phonology should be organized, for primary and secondary teachers of English, where, among other things, priority and emphasis should be given to create an awareness, among the participants, of the problem of L1 interference in spoken English and the lack of intelligibility. The target areas, as pointed out in this study, should be highlighted by playing the 
recordings of some of the representative speech samples of the Libyan English speakers.

a) For splitting the clusters in the word-final positions, it should be demonstrated how it happens, and how to produce them correctly. Intensive pronunciation drills should be given, selecting some clusters which contain different phonemes.

b) Similarly, for the problem of starting three-consonant clusters with an epenthesis /i/, it should be properly demonstrated with a few clusters, to drive home the problem that the clusters spilt when they start with /i/. Training the teachers will certainly result in better speech by the students.

2) Trained teachers can use the above methodology in their classroom teaching.

3) Keeping in mind the EFL situation, courses offered at the university departments, in phonetics and phonology, should give greater weight to pronunciation drills, speech practice and production of free speech, keeping the theoretical aspects of phonological features, to the minimum. 


\section{REFERENCES}

1- ANDERSON, JANET. 1987. The markedness differential hypothesis and syllable structure difficulty. In Georgette Ioup, and Steven Weinberger (eds.). Interlanguage Phonology: The Acquisition of a Second Language Sound System, 279-291. New York: Newbury House/Harper and Row.

2- ARChIBALD, John, and TERESA VANDERWEIDE. 1996. L2 syllable structure: derived sonority and typological universals. Paper presented at the Alberta Conference on Linguistics.

3- BeCKMAN, JiLL. 1998. Positional Faithfulness. Doctoral Dissertation. University of Massachusetts.

4- Bernhardt, BARbArA, and Joseph STEMBERger. 1998. Handbook of Phonological Development. New York: Academic Press.

5- Broselow, Elllen, Sui Chen, and Chilin Wang. 1998. The emergence of the unmarked in second language phonology. Studies in Second Language Acquisition 20, 261-280.

6- CARLiSLe, Robert. 1988. The effect of markedness on epenthesis in Spanish/ English interlanguage phonology. IDEAL 3, 15-23.

7- . 1994. Markedness and environment as internal constraints on the variability of interlanguage phonology. In Mehmet Yavas (ed.). First and Second Language Phonology, 223249. San Diego, CA: Singular.

81997. The modification of onsets in a markedness relationship: Testing the interlanguage structural conformity hypothesis. Language Learning 47, 327-361.

91998. The acquisition of onsets in a markedness relationship: A longitudinal study.

10- ECKMAN, FRED. 1977. Markedness and the contrastive analysis hypothesis. Language Learning 27, 315-330.

$11-$ .1991. The structural conformity hypothesis and the acquisition of consonant clusters in the interlanguage of ESL learners. Studies in Second Language Acquisition 13, 23-41. 
12- ECKMAN, FRED, and GREGORY IVERSON. 1993. Sonority and markedness among onset clusters in the interlanguage of ESL learners. Second Language Research 9, 234-252.

$13-$ . 1994. Pronunciation difficulties in ESL: Coda consonants in English interlanguage. In Mehmet Yavas (ed.). First and Second Language Phonology, 251-266. San Diego, CA: Singular.

14- HANSEn, JetTE G. 2003. Developmental sequences in the acquisition of English L2 syllable codas. Studies in Second Language Acquisition 26, 85-124.

15- Janet C.E Watson. The Phonology and Morphology of Arabic, Oxford University Press, 2002, 2007.

16- KIM, KWANG. 2001. Chodunghakseng yeongeojaumgun palumsangui moumsapipgwa chaum tallak oryu punseok (Epenthesis and deletion in the interlanguage of Korean elementary school children). MA thesis. University of Incheon.

17- KIM, Mi-JEONG. 1991. Yeongeo caumgun palume isseo moumsapip hyeonsangedaehan yeongu (A study of epenthesis in the pronunciation of English consonant clusters). MA thesis. Yonsei University.

18- LADO, ROBERT. 1957. Linguistics across Cultures. Ann Arbor: University of Michigan Press.

19- LeE, Shinsook, JeOngsoon JoH, and Mi-Hui Cho. 2002. Acquisition of English consonant clusters among Korean EFL learners. Korean Journal of Linguistics 27, 439-472.

20- MAJOR, Roy. 2001. Foreign Accent. Mahwah: Lawrence Erlbaum Associates.

21- MAJOR, ROY, and MichAEl FAUDREE. 1996. Markedness universals and the acquisition of voicing contrasts by Korean speakers of English. Studies in Second Language Acquisition 18, 69-90.

22-SATO, CHARLENE. 1984. Phonological processes in second language acquisition: Another look at interlanguage syllable structure. Language Learning 34, 43-57. 
23- WEINBERGER, STEVEN. 1987. The influence of linguistic context on syllable simplification. In Georgette Ioup, and Steven Weinberger (eds.). Interlanguage Phonology: The Acquisition of a Second Language Sound System, 401-417. New York: Newbury House/Harper and Row. 


\section{Appendix}

The written samples, which were read by the candidates and recorded and analyzed, have been picked up and presented here, along with their phonetically transcribed texts. After each sample, a table follows, along with the analysis and comments.

a) Sample -1

\section{Passage for two and three consonant clusters in coda}

"He talks to his friends everyday about the things he does in his office.

We three friends meet often and discuss the films we have seen at Sindbad Restaurant. We sit there until the waiter removes the tables. But on Sundays we have different programs."

Phonetic transcription of the above text with deviation

hi: təkis to hIz frendız əbəut də tingIz hi: $\mathrm{d} \Lambda \mathrm{z}$ in hız əfis. wi: tri: frendız mi:t əfen ond diskıs də filmız wi: hæv si:n æt sindbæd restprənt. Wi: sit deə $\Lambda$ ntıl də we: to ri:mu:viz də terblız bıt pn sınde:z wi: hæv difərənt brəgræmız.

\section{Sample- 2}

Passage for two and three consonant clusters in onset

"Stray dogs ran along the street. Often they could be seen around the spring water: some drinking the water and some just standing, looking at the stream. Sometimes, school children could be seen crowding around the area to see the spring water gushing out. Some children splashed the water screaming with laughter."

The phonetic transcription of the above text with deviation: Istre I dogəz ræn əlpy də Istri:t. əfen deI kod bi si:n əraund də Isbry wətər səm drinking də wətər ənd dz $\Lambda$ st stænding lokıng ət də Istri:m səmtaiməz sku:l tfildərən kod bi si:n krauding oraond də eirı tu si: də Isbring wətər $\mathrm{g}_{\Lambda} \int \mathrm{f} n g$ aut səm tfildərən Isblæfid də wətər Iskri:ming wid la:ftər 